\title{
Shallow soil effects for contrasting peak ground accelerations at nearby strong-motion stations during the 2017, Mj 5.2, southern Akita Prefecture earthquake
}

\author{
Yadab P. Dhakal*, Wataru Suzuki, Takeshi Kimura, Takashi Kunugi, Shin Aoi \\ National Research Institute for Earth Science and Disaster Resilience, Tsukuba, Japan \\ *Corresponding author's email: ydhakal@bosai.go.jp
}

\begin{abstract}
On September 8, 2017, an earthquake of Mj 5.2 occurred with the epicenter in southern Akita Prefecture, Japan, at 22:23 local time. According to the Japan Meteorological Agency, the focal depth was $9 \mathrm{~km}$. Many strong-motion stations of K-NET and $\mathrm{KiK}$-net recorded ground motions from the earthquake. The maximum horizontal vector peak ground acceleration (PGA) of approximately $136 \mathrm{~cm} / \mathrm{s}^{2}$ was recorded at one of the KiK-net stations at an epicentral distance of about $8 \mathrm{~km}$. However, despite being $37 \mathrm{~km}$ and $53 \mathrm{~km}$ far from the epicenter, two stations recorded PGAs of approximately 126 and $113 \mathrm{~cm} / \mathrm{s}^{2}$, respectively, similar to that near the epicenter. Even though these PGAs are not rare, we found that the PGAs at the two sites strongly deviated from the median values suggested by a ground motion prediction equation (GMPE), while the nearby sites generally followed the GMPE. Available velocity models showed that shallow shear wave velocities, especially in the top $5 \mathrm{~m}$, were lower (i.e., the soils were softer) at the two sites compared to those at their nearest neighboring sites. We compared the ratios of the PGAs and peak ground velocities (PGVs) at the two sites with respect to their neighboring sites for many earthquakes covering a wide range of magnitudes and azimuths. We found that the PGAs and PGVs at the two sites were systematically larger than those at the adjacent sites. Linear theoretical site amplifications using the available soil models gave peak frequencies around 6-8 Hz at the larger PGA sites. Bandpass-filtered records showed significantly larger PGAs around these frequencies at the larger PGA sites. The above results showed that local site condition is one of the major contributing factors to induce large PGAs. Furthermore, softer sites experience more substantial nonlinear site amplification than the stiffer sites when input motions exceed some threshold PGAs. This latter effect means that the softer sites can produce a variety of ground motion spectra. Nevertheless, the degree of damage to built structures depends on several factors, including the design and quality of construction. We expect that this study contributes to developing improved microzonation maps for earthquake disaster mitigation.
\end{abstract}

Keywords: Southern Akita Prefecture Earthquake; Ground motions; PGA; PGV; Site amplification

Received: 31 May, 2021 Received in revised form: 25 June, 2021 Accepted: 3 July, 2021

\section{INTRODUCTION}

Soft soils are ubiquitous near the surface of the earth. Analysis of site amplification due to shallow soils is essential in seismic hazard estimation. Earthquake ground motions recorded at a site may be explained by the combined effects of the source, path, and local site condition. Sometimes, the site effect dominates the recorded ground motions, especially at the site of unconsolidated sediments due to the amplification of waves impinging at the base of sedimentary layers (e.g., Celebi et al., 1987). Therefore, understanding the reason for the large ground motions provides insight into the seismic microzonation study and mitigation planning for earthquake disasters (e.g., Kawase 1996, Pinzón et al., 2019). Permanent network of strongmotion stations provides an opportunity to unravel the reasons for the large ground motions during a major earthquake. However, the spatial separation of observation stations in a permanent network is still wide and temporary deployment of dense seismic observation stations is common in the damaged area after a major earthquake for the damage investigations (e.g., Yamanaka et al., 2016; Bijukchhen et al., 2017).

In this paper, we analyzed the strong-motion data recorded at two pairs of permanent strong-motion observation sites, where we noticed that one of the sites of each pair recorded significantly larger peak ground acceleration (PGA) than that at the other site, during the $2017 \mathrm{Mj} 5.2$ southern Akita Prefecture earthquake, despite that the sites of each pair were in close proximity. It was found that the larger PGAs were recorded at the sites with lower S-wave velocities in the upper few meters. The strong-motion stations belong to the K-NET and KiK-net operated by the National Research Institute for Earth Science and Disaster Resilience (NIED) (Okada et al., 2004; NIED 2019; Aoi et al., 2020). The earthquake occurred on September 8, 2017, at 10:22 local time (Japan Standard Time). The above magnitude notation, $\mathrm{Mj}$, refers to the Japan Meteorological Agency (JMA) magnitude. 
The moment magnitude $(\mathrm{Mw})$ of the earthquake estimated by F-net NIED was 4.9. The JMA focal depth was $9 \mathrm{~km}$ (rounded to the nearest integer). The epicenter of the earthquake and the station pairs are shown in Fig. 1. The map also depicts the aftershocks within 24 hours of the earthquake and active faults (Research Group for Active Faults of Japan, RGAFJ 1991) around the epicenter. The 2017 southern Akita Prefecture earthquake is hereafter simply referred to

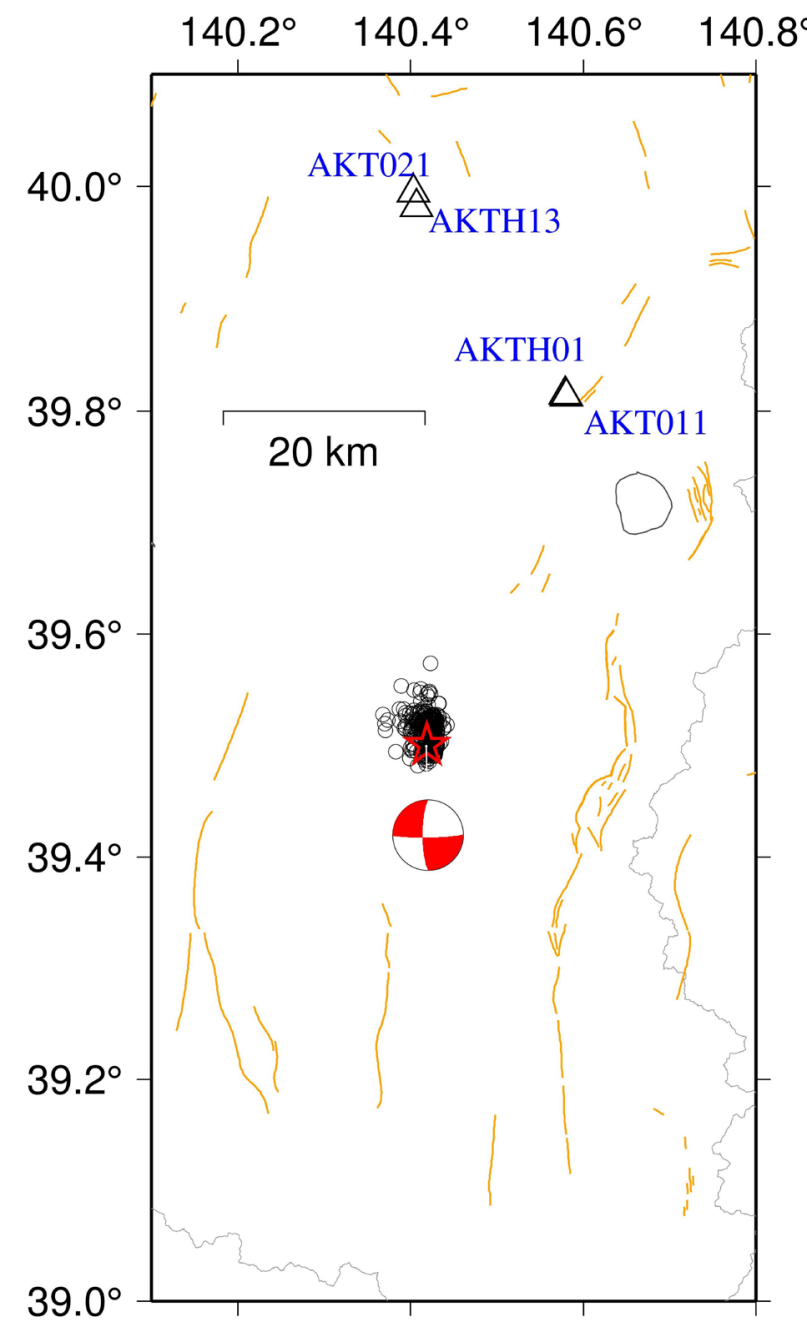

Fig. 1: Index map. Star denotes the epicenter of the 2017 Mj 5.2 earthquake. The focal mechanism plot of the earthquake (F-net NIED) is shown below the epicenter. Circles indicate the aftershocks within 24 hours after the origin time of the earthquake. Triangles denote the target sites in the present study. Orange line segments denote the active faults in the region (RGAFJ 1991).

as the 2017 AP earthquake.

In the present paper, the two sites with site codes, AKT011 and AKTH01, make a pair, and the other two sites with site codes, AKTH13 and AKT021, make another pair (see Fig. 1). The former and the latter pairs are hereafter called the first and second pairs, respectively. The interstation distance between the stations of the first pair is about $250 \mathrm{~m}$, while the separation is approximately $1.5 \mathrm{~km}$ between the stations of the second pair. The site AKTH01 of the first pair is located at an epicentral distance of about $37 \mathrm{~km}$, while the site AKTH13 of the second pair is located about $53 \mathrm{~km}$ far from the epicenter. The spatial distribution of the observed horizontal vector PGAs at the K-NET and KiK-net stations during the 2017 AP earthquake is shown in Fig. 2. The vector PGAs recorded at the first pair of stations, AKT011

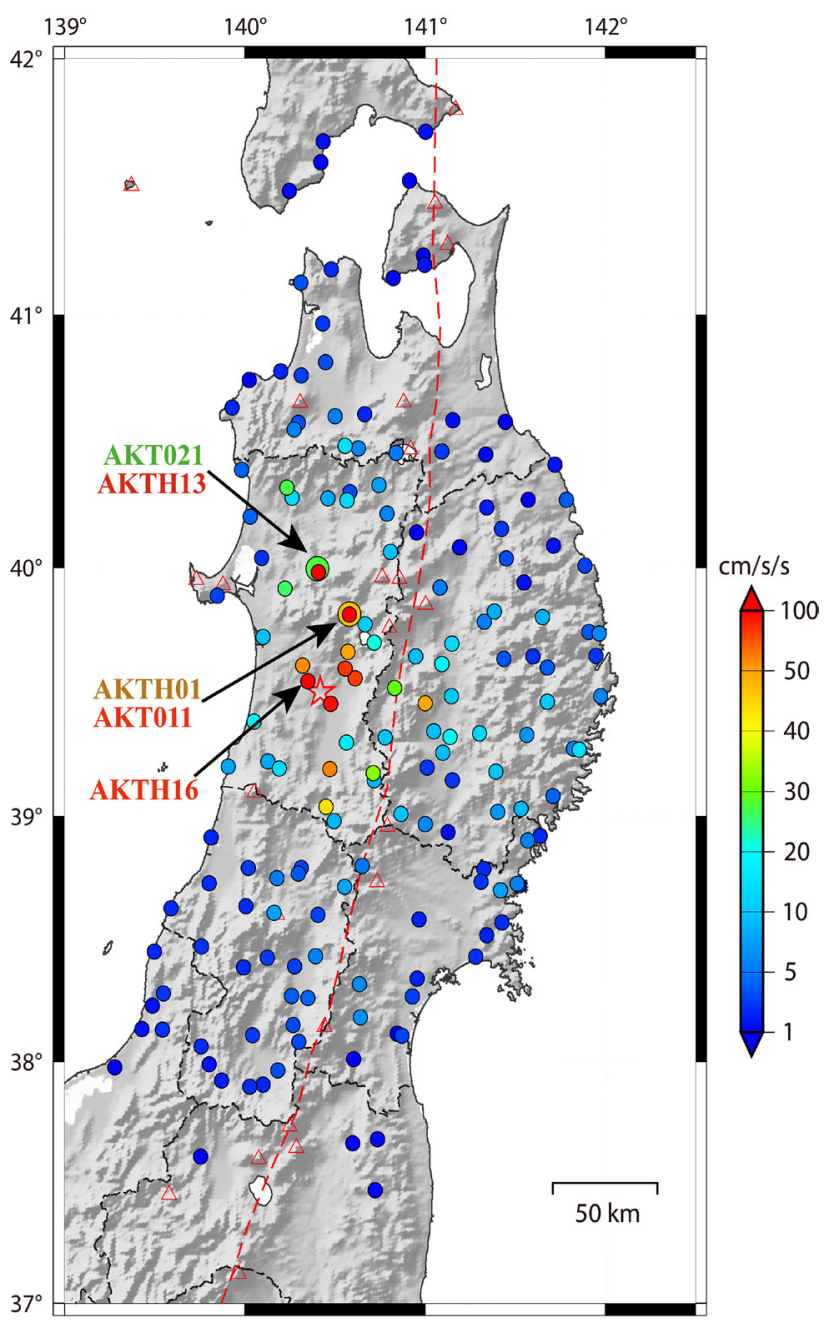

Fig. 2: Spatial distribution of the horizontal vector PGA at the strong-motion observation sites (circles). A larger circle shows one of the stations of each target pair for clarity as the locations overlap in a small-scale drawing. The triangles denote active volcanoes and dashed red line volcanic front line.

and AKTH01, were approximately 126 and $40 \mathrm{~cm} / \mathrm{s}^{2}$, respectively.

Similarly, the vector PGAs recorded at the second pair of stations, AKTH13 and AKT021, were around 113 and $28 \mathrm{~cm} / \mathrm{s}^{2}$, respectively. The maximum horizontal vector PGA of $133 \mathrm{~cm} / \mathrm{s}^{2}$ was recorded at the site AKTH16 close to the epicenter (see Fig. 2 for the site location). Considering the small magnitude of 
the earthquake, large epicentral distances, and small inter-station separations, the source effects such as the directivity effect and path effect may be considered similar at the sites of corresponding pairs. Therefore, the site amplification effect is the most plausible explanation for the large variation of the PGAs at the stations of each pair mentioned above. The spatial distribution plot in Fig. 2 indicates other possible pairs of stations where noticeably different PGAs were observed. However, the selected pairs of stations are interesting due to the larger PGA values.

Below, first, we compare the observed PGAs during the $\mathrm{Mj} 5.2$ event with a commonly used ground motion prediction equation (GMPE) in Japan. Then, the velocity profiles and site amplification at the recording stations under consideration are discussed. Then, we compare the acceleration waveforms and their peak values at different frequency bands. Finally, we conclude by examining the PGAs and PGVs at the pair of sites for several earthquakes in terms of magnitude, source-to-site distance, focal depths, and back azimuths.

\section{COMPARISON OF PGA WITH GMPE}

A simple approach to evaluate observed peak motions is to compare the values with the GMPEs constructed for the region. There are several GMPEs in Japan for PGAs and other strong-motion parameters. In this paper, we selected the GMPE for PGA by Si and Midorikawa $(1999,2000)$, which has been widely used in Japan. Si and Midorikawa (1999) developed the GMPE for larger PGA of the two horizontal components for soil site conditions. It has been known that the PGA at a soil site is generally larger than the PGA at a rock site. For example, Si and Midorikawa (1999) found that the PGA at a soil site was, on average, larger by a factor of 1.4 than the average value at a rock site.

We corrected the acceleration records for baseline shifts and applied low-cut filtering at $0.1 \mathrm{~Hz}$ to remove long-period noises. Then, PGA was obtained for each component of the three-component recordings. Here, the larger PGA of the two horizontal components is taken for comparison with the GMPE, similar to the definition of PGA in Si and Midorikawa(1999, 2000).

The PGAs recorded during the 2017 AP earthquake are plotted in Fig. 3 as a function of hypocentral distance. Prediction curves using the equation in $\mathrm{Si}$ and Midorikawa $(1999,2000)$ are also drawn for the earthquake. It can be seen that the data generally follow the prediction curves for the magnitude of the event. However, the values at the two sites, namely AKT011 and AKTH13, lie significantly above the curve of plus one standard deviation. The values at their corresponding nearest sites, AKTH01 and

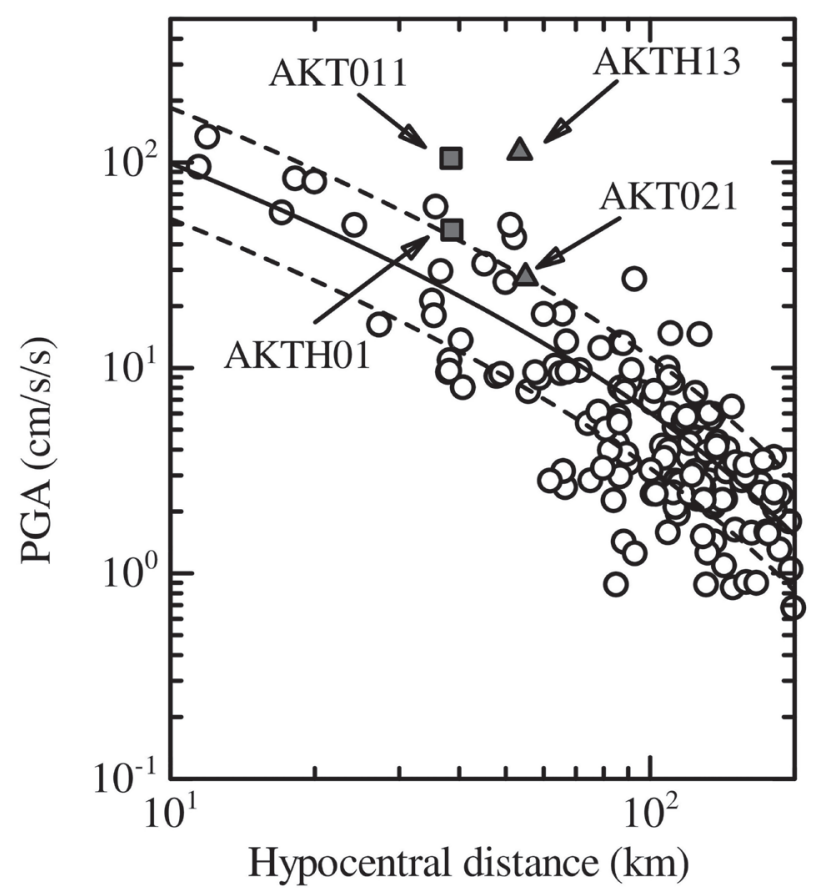

Fig. 3: The plot of the larger horizontal component PGAs (circles) against the hypocentral distance. The solid line is the prediction curve using the equation in Si and Midorikawa (1999) for the crustal event of Mw 4.9, focal depth $9 \mathrm{~km}$, and soil site condition. The dashed lines denote plus-minus one standard deviation. Squares show the values for the target station pair AKT011 and AKTH01 and triangles for the other target station pair AKTH13 and AKT021. The site codes are indicated for each target pair in the plot.

AKT021, indicated in the plots, are very close to the curve of plus one standard deviation.

\section{VELOCITY PROFILES AND SITE AMPLIFICATION}

The PS-logging velocity profiles are available down to the depth of $10 \mathrm{~m}$ at the K-NET sites AKT011 and AKT021. On the other hand, the PS-logging velocity profiles are available down to the extent of $103 \mathrm{~m}$ at the sites AKTH01 and AKTH13. The S-wave velocity (Vs) profiles at the sites are plotted in Fig. $4(\mathrm{a}, \mathrm{b})$. The depth and velocity scales are shown in the log-scale to show the small values clearly in the figure. It can be seen that the velocity models mostly differ at the top five-meter of soil column in each pair. The soils at the AKT011 and AKTH13, where the larger PGAs were observed, have lower S-wave velocities than those in their neighboring sites. Deep subsurface velocity model down to the upper crust of Vs $3.4 \mathrm{~km} / \mathrm{s}$ has been made available through Japan Seismic Hazard Information Station (J-SHIS) (Fuiwara et al., 2009, J-SHIS 2020). We examined the J-SHIS subsurface velocity model and found that the deep subsurface models were identical at the neighboring stations of the pairs. Assuming that the velocity profiles below 10 $m$ at the K-NET sites AKT011 and AKT021 are similar 
to their corresponding nearby sites, we computed the theoretical S-wave amplification factors at the surface for vertically incident plane waves at a depth of 100 $\mathrm{m}$, at which borehole seismometers were installed at the KiK-net sites.

We used the propagator matrix method to compute the site amplification (Ch. 5, Aki and Richards 2002), assuming vertically propagating plane $\mathrm{S}$ wave. For the computation, the density values, which were not available at the KiK-net sites (here AKTH01 and AKTH13), were estimated using the empirical equation shown below.

$$
\rho=1.4+0.67 \sqrt{V_{S}}
$$

where $\rho$ is density in $\mathrm{g} / \mathrm{cm}^{3}$ and Vs is in $\mathrm{km} / \mathrm{s}$, as used in Nagashima et al. (2014). We used the tentative Qs value equal to $\mathrm{Vs} / 10$ for each layer, where $\mathrm{Vs}$ is in $\mathrm{m} / \mathrm{s}$, as the Qs values were not available. The in situ Qs values can vary from site to site, and need to be evaluated for each site for accurate description of site amplification (e.g., Kudo and Shima 1970, Yamamizu et al., 1983). The level of amplification varies with the change of Qs values, but the peak frequency generally remains the same. The Qs values used in this study are towards the lower end and are reasonable for our purpose. The linear site amplification factors obtained in this study are plotted in Fig. 4(c, d). It can be seen that the amplification factors at the sites AKT011 and AKTH13, where large PGAs were observed, show large and distinct peaks at around 7.7 and $7.9 \mathrm{~Hz}$, respectively. The prominent peak at AKTH13 (Fig. (a)

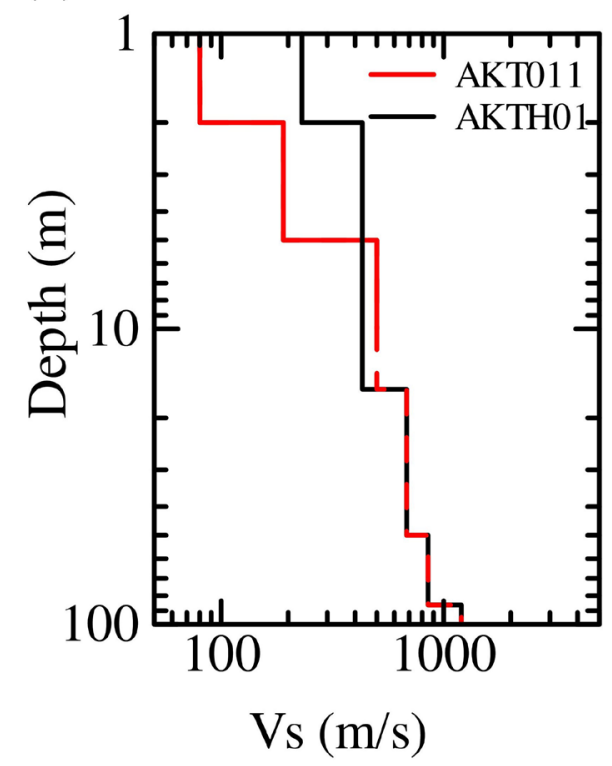

(c)

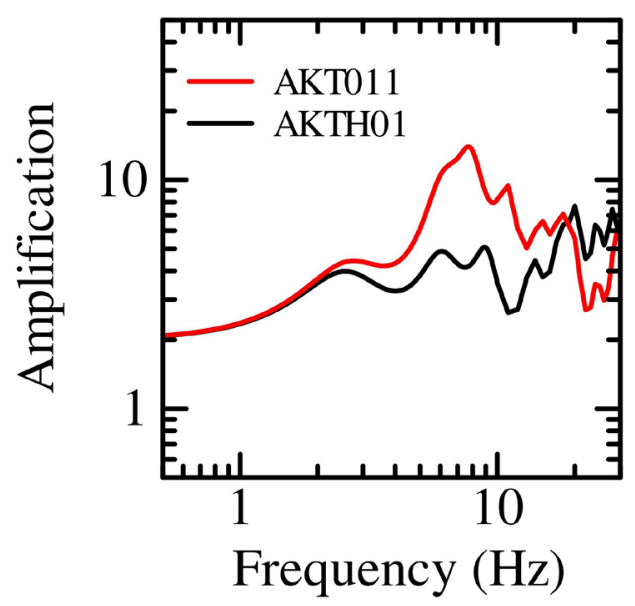

(b)

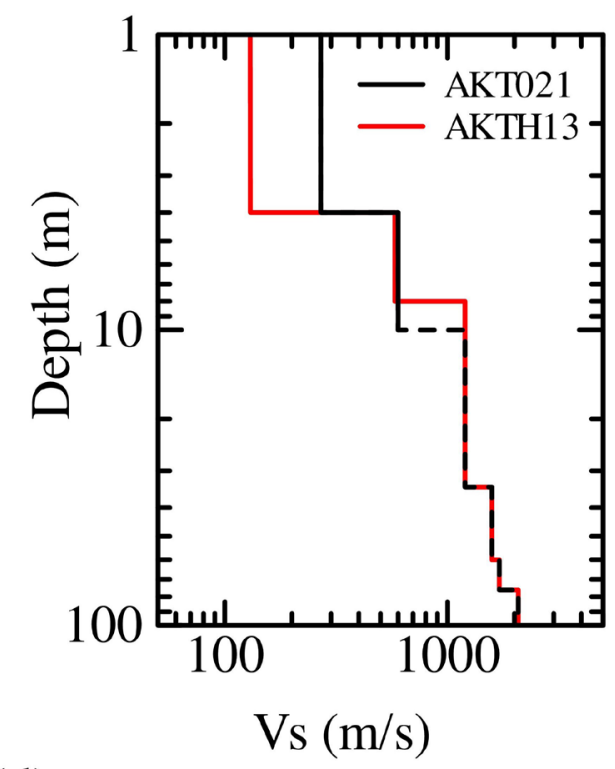

(d)

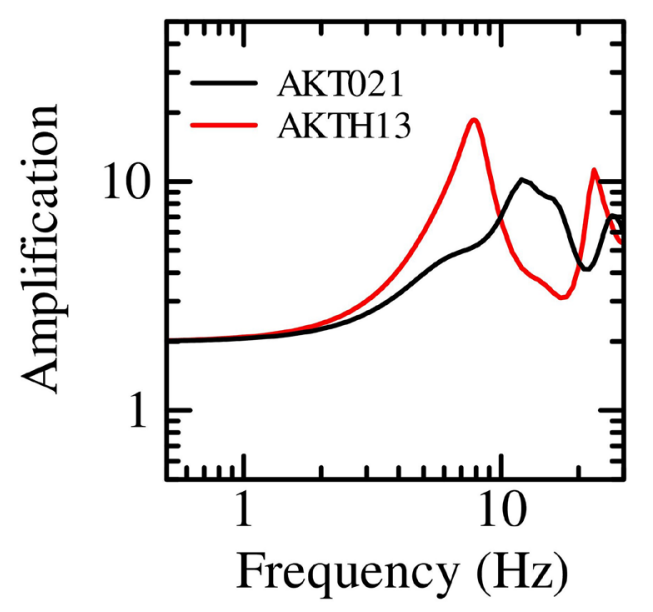

Fig. 4: Upper panels: S-wave velocity profiles based on PS-loggings for station pairs: AKT011 and AKTH01 (a), AKTH13 and AKT021 (b). The broken portions of the profile lines for AKT011 and AKT021 (below $10 \mathrm{~m}$ ) are the extrapolations to match the profiles of the nearest sites AKTH01 and AKTH13, respectively. Lower panels (c, d): Theoretical S-wave amplifications at sites indicated in each panel for vertical incidence plane SH waves using the velocity profiles of the corresponding sites plotted in (a) and (b). 
4d) may be related to the significant velocity contrast between the upper two layers. A simple equation, $\mathrm{T}=$ 4H/Vs (e.g., Kramer 1996), using the parameters of the uppermost layer $(\mathrm{H}=4 \mathrm{~m}$ and $\mathrm{Vs}=130 \mathrm{~m} / \mathrm{s})$, gives a peak frequency of $\sim 8.1 \mathrm{~Hz}$, which is close to the peak frequency of $7.9 \mathrm{~Hz}$ from the whole layers. The site AKT011 consists of two sublayers at the top with small S-wave velocities (Fig. 4a). The peak frequency computed after averaging the S-wave velocities in the upper two layers is around 6.6, which is somewhat smaller than the peak frequency of $7.7 \mathrm{~Hz}$ (Fig. 4c) using the whole layers (Fig. 4a).

It is interesting to check whether the theoretical peak frequencies and peak amplifications correspond to the observed amplification factors. The surfaceto-borehole spectral ratios for the S-wave part of the observed recordings may be considered to be a proxy to S-wave site amplification (Rodríguez and Midorikawa 2003). The spectral ratios for the NS and EW components at the site AKTH13, which recorded the large PGA, are shown in Fig. 5. It can be seen that the peak frequencies of the spectral ratios $(\sim$ $7.8 \mathrm{~Hz}$ for the EW component, and $\sim 8.6 \mathrm{~Hz}$ for the NS component) generally match with the theoretical peak frequencies in Fig. 4(d). The mismatch between the observed and theoretical peak frequencies is anticipated because the velocity models may differ from the actual velocities, and the angle of incidence may not be truly vertical. However, it should be noted that the borehole records are affected by downgoing waves, and hence the peak spectral ratios do not necessarily represent the site amplification (Steidl et al., 1996).

\section{PEAK VALUES AT MULTIPLE FREQUENCY BANDS}

The acceleration seismograms at the first pair of stations, AKT011 and AKTH01, are plotted for the EW component in Fig. 6. The plots are shown for original records without filtering in 6 (a), and for three frequency bands $0.5-3 \mathrm{~Hz}, 3-10 \mathrm{~Hz}$, and $10-30 \mathrm{~Hz}$ in 6(b), (c), and (d), respectively. The PGA is 101.7 $\mathrm{cm} / \mathrm{s}^{2}$ at AKT011while it is $40.8 \mathrm{~cm} / \mathrm{s}^{2}$ at AKTH01. The ratio of PGAs is around 2.5. The PGAs are 9.2 (3.6), $78.9(24.8)$, and $24.5(21.3) \mathrm{cm} / \mathrm{s}^{2}$, respectively, at the three frequency bands at the sites AKT011 (AKTH01). The largest PGA is from the frequency band of 3 to $10 \mathrm{~Hz}$ at both stations, and the ratio of the largest PGAs is around 3.2. In Fig. 4 (c), it can be seen that the amplification factors are larger at frequencies of 3 to $10 \mathrm{~Hz}$ at the ATK011 site. The PGA ratios were generally similar for the NS components as well.

Similarly, the acceleration seismograms at the second pair of stations, AKTH13 and AKT021, are plotted for the EW component in Fig. 7. The plots are shown for original records without filtering in 7 (a) and for three frequency bands $0.5-3 \mathrm{~Hz}, 3-10 \mathrm{~Hz}$, and $10-30 \mathrm{~Hz}$ in 6(b), (c), and (d), respectively. The PGA is $112.5 \mathrm{~cm} / \mathrm{s}^{2}$ at AKTH13 while it is $27.5 \mathrm{~cm} / \mathrm{s}^{2}$ at AKT021. The ratio of PGAs is around 4.0. The PGAs are 3.9 (4.5), $95(20)$, and $28.6(7.7) \mathrm{cm} / \mathrm{s}^{2}$ at the three frequency

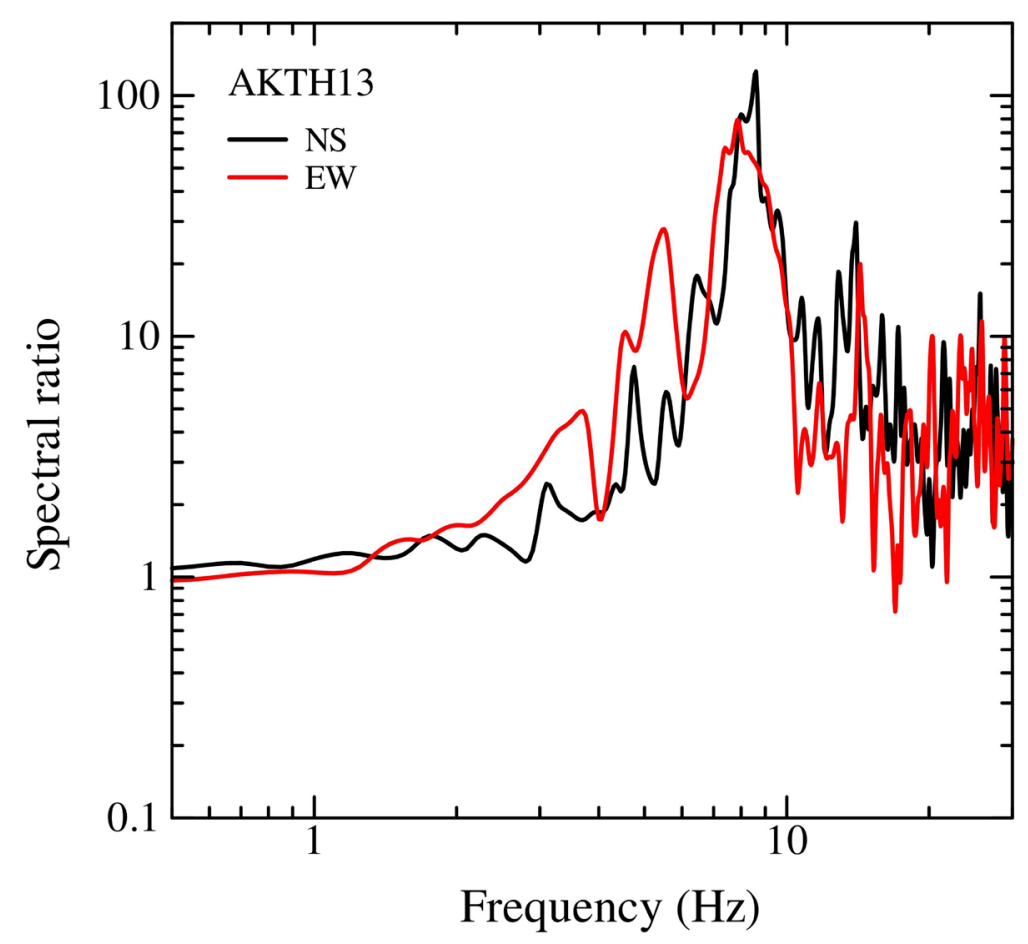

Fig. 5: Surface-to-borehole spectral ratios of horizontal component recordings at the site AKTH13 for the 2017 southern Akita Prefecture earthquake. 
(a)

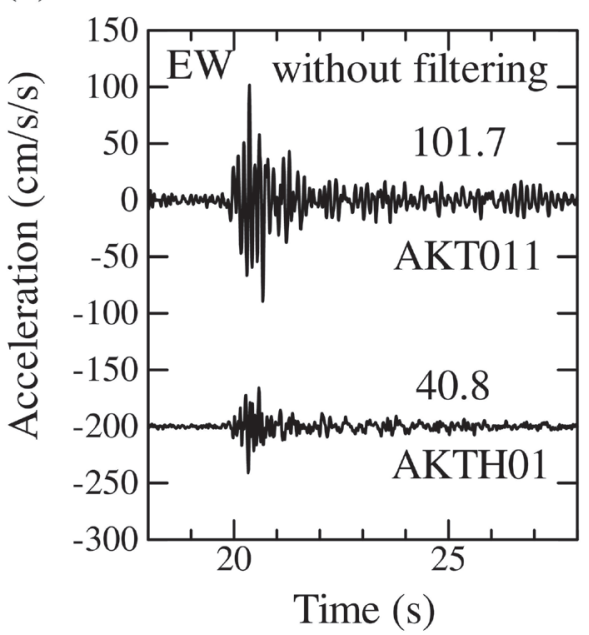

(c)

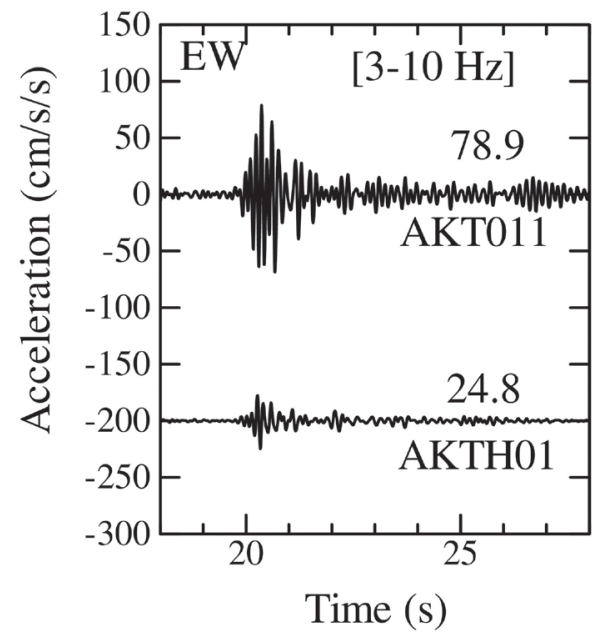

(b)

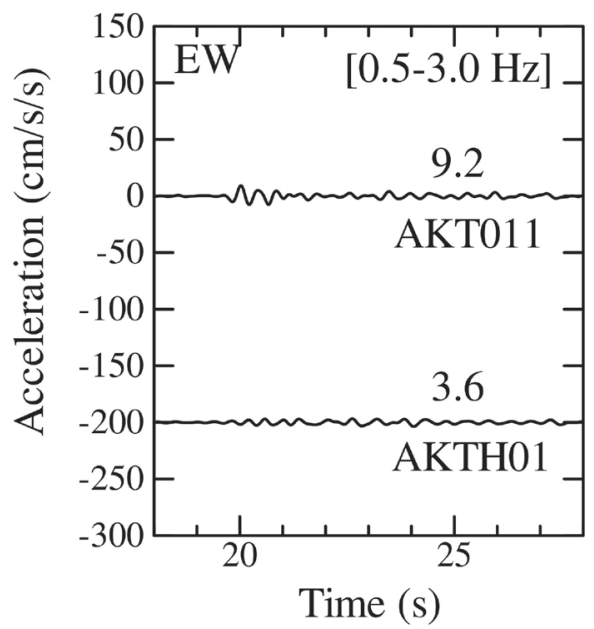

(d)

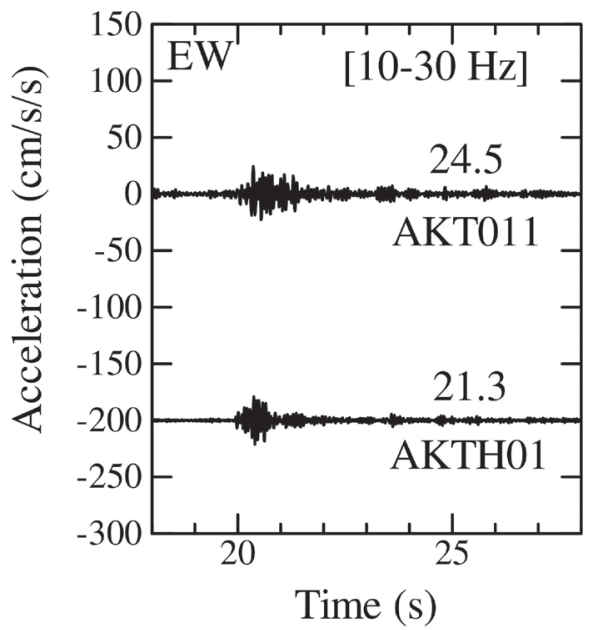

Fig. 6: Comparison of EW component acceleration waveforms and peak values at the first pair of stations (AKT011: upper trace, AKTH01: lower trace). Panel (a) shows the traces without filtering, while panels (b), (c), and (d) show the traces for three frequency bands as indicated in each panel, respectively. The numeral above each trace is the peak value for the trace.

bands at the sites AKTH13 (AKT021). The largest PGA is from the frequency band of 3 to $10 \mathrm{~Hz}$ at both stations, and the ratio of the largest PGAs is around 4.7. In Fig. 4 (d), it can be seen that the amplification factors are larger at frequencies of 3 to $10 \mathrm{~Hz}$ at the ATKH13 site; the amplification factor at the peak frequency of $7.9 \mathrm{~Hz}$ at ATKH13 is larger by a factor of around 3.5 compared to the amplification factor at the frequency at AKT021. The PGA ratios for the NS components were also generally similar to those for the EW components.

\section{PEAK RATIOS FOR SEVERAL EARTHQUAKES}

We examined the ratios of the PGAs for several earthquakes recorded at the two pairs of stations to confirm that the difference of PGAs at the corresponding stations was not specific to the 2017 AP earthquake. We selected the records from earthquakes with epicenters within $300 \mathrm{~km}$ of the stations AKT011 and AKTH13 for the first and second pairs, respectively. The two stations recorded the larger PGAs of the corresponding pairs during the 2017 AP earthquake. The records that contained the arrival of S-waves were selected. The acceleration waveforms and Fourier spectra for all the earthquakes were visually examined for spurious signals. The records were low-cut filtered at $0.1 \mathrm{~Hz}$ to minimize the low-frequency noises. The epicenters of the selected events for the two pairs of stations are depicted in Fig. 8 , and the source parameters are listed in Appendix 1. The numbers of events are 28 and 13 for the first and second pairs of stations, respectively. The number of events differed between the two pairs of stations as the stations on stiffer sites were not triggered for some earthquakes. The magnitudes of the events ranged between 3.8 and 9, and the events distributed mostly in the backazimuths of $90^{\circ}-180^{\circ}$ for the both pairs of stations. The azimuthal coverage is weak in the range of $180^{\circ}-270^{\circ}$. 
(a)

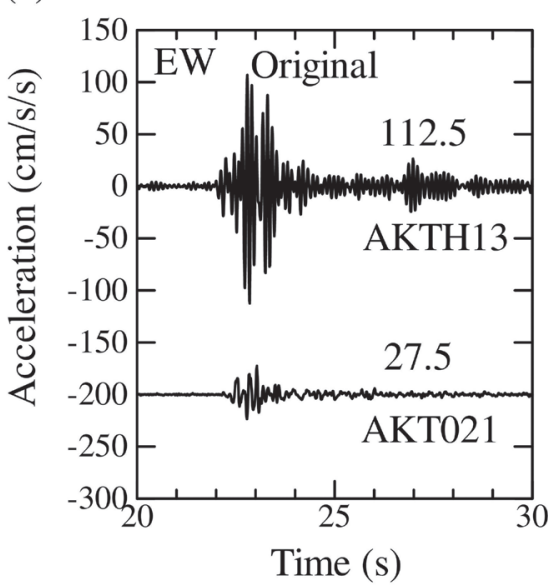

(c)

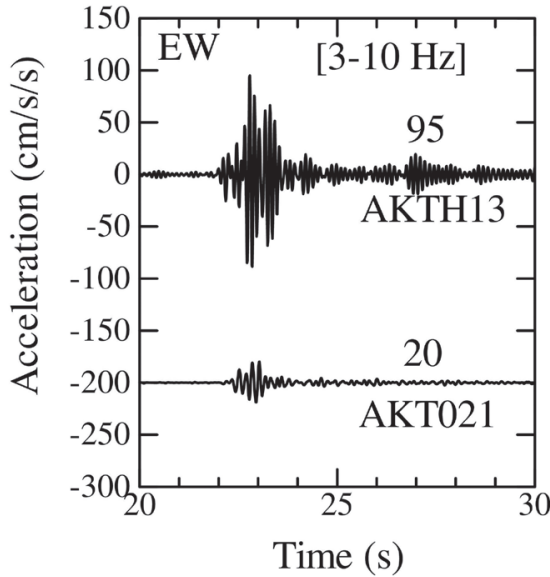

(b)

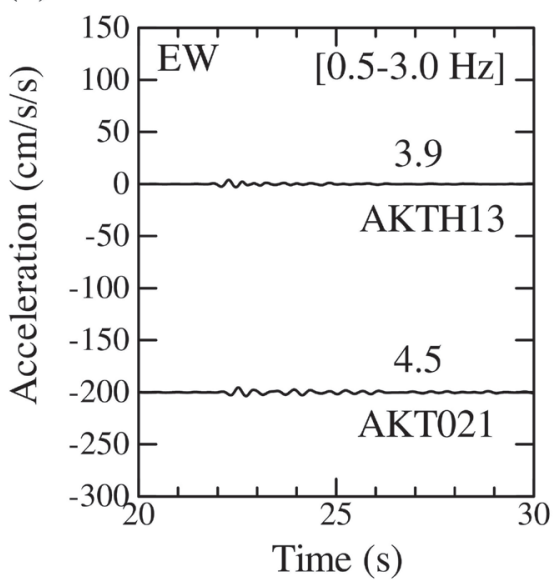

(d)

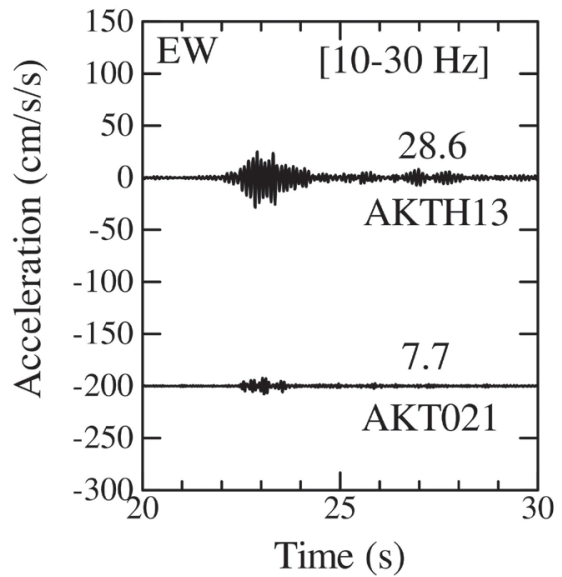

Fig. 7: Comparison of EW component acceleration waveforms and peak values at the second pair of stations (AKTH13: upper trace, AKT021: lower trace). Panel (a) shows the traces without filtering, while panels (b), (c), and (d) show the traces for three frequency bands as indicated in each panel, respectively. The numeral above each trace is the peak value for the trace.
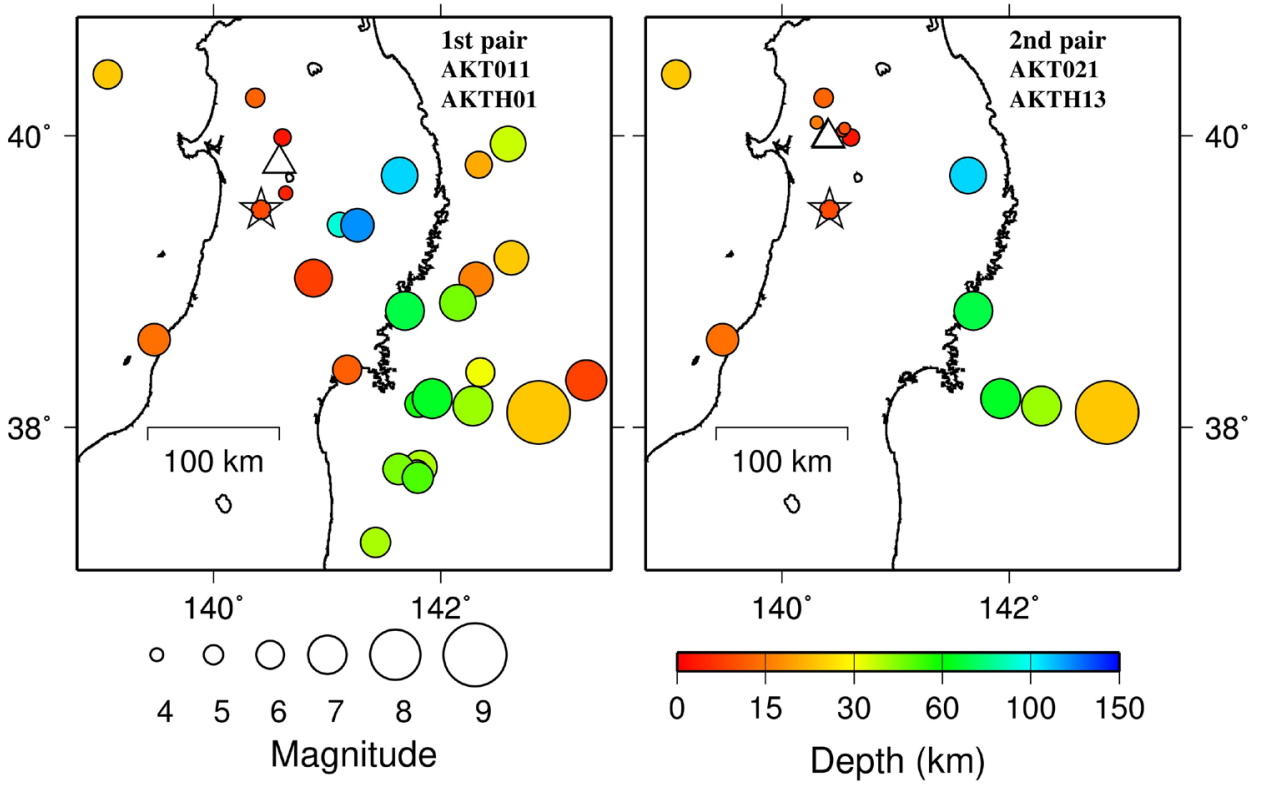

Fig. 8: Location of epicenters of events (circles) used for the comparison of the PGAs and PGVs at the first station pair AKT011 and AKTH01 (left panel) and AKTH13 and AKT021 (right panel). The star denotes the epicenter of the 2017, Mj 5.2 Southern Akita Prefecture earthquake. The triangles in the left panel denote the station pair AKT011 and AKTH01, while they denote the station pair AKTH13 and AKT021 in the right panel. The station locations overlap due to a small scale in each panel. 
The ratios of PGAs for the first pair of stations AKT011 and AKTH01 are plotted as a function of epicentral distance in Fig. 9 (a, c) and $(b, d)$ for the NS and EW components, respectively. The ratios are color-coded by the magnitude and focal depths for each component, as indicated in the plots. The mean PGA ratios computed from 28 events were around 2.4 and 2.1 for the NS and EW components, respectively. The ratios did not show dependency on the magnitude or focal depth. But, a slight dependence on distance can be seen on the NS component; the ratios for distances smaller than about $200 \mathrm{~km}$ are somewhat larger than those beyond $200 \mathrm{~km}$. A similar tendency was observed for the PGA ratios between (a)

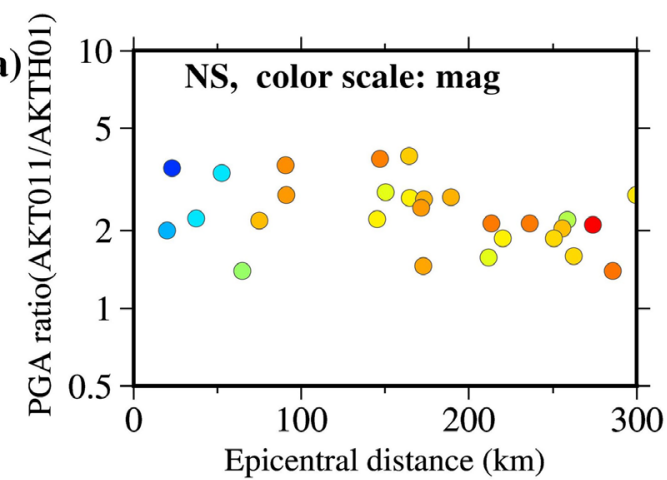

(c)

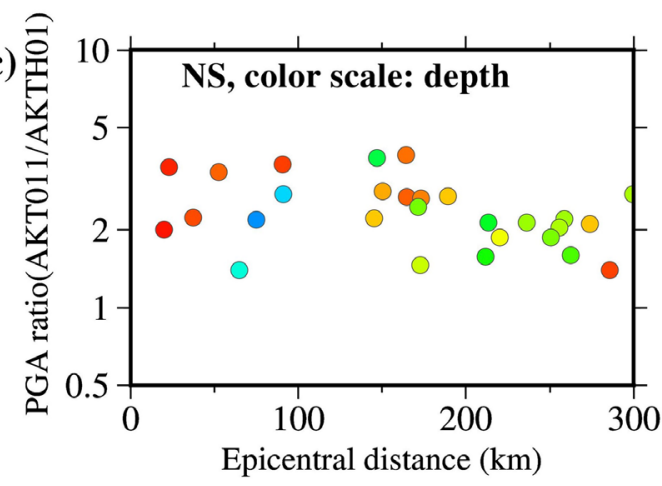

(e)

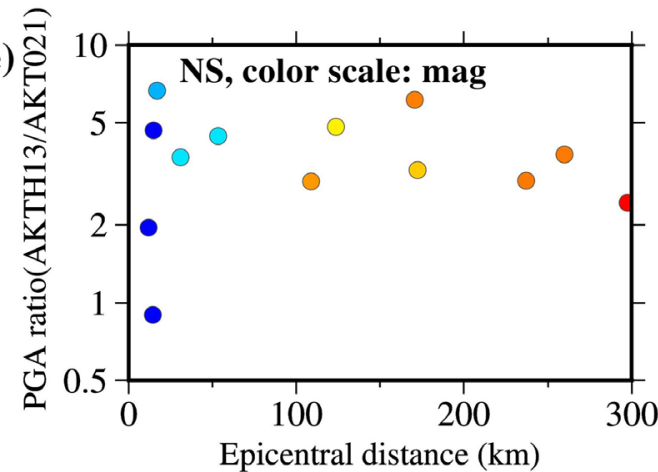

(g)

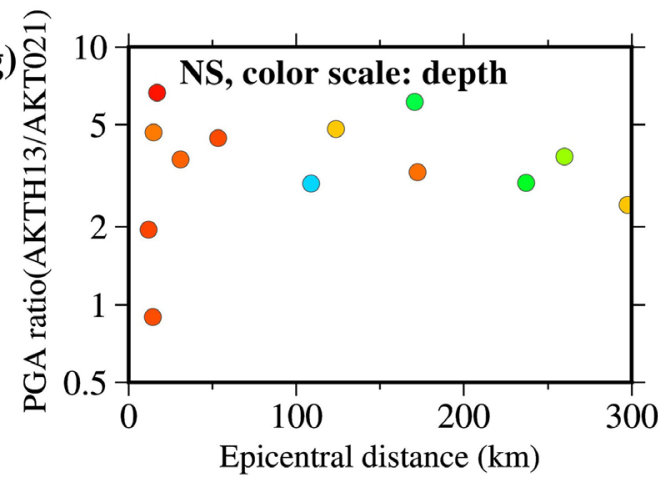

(b)
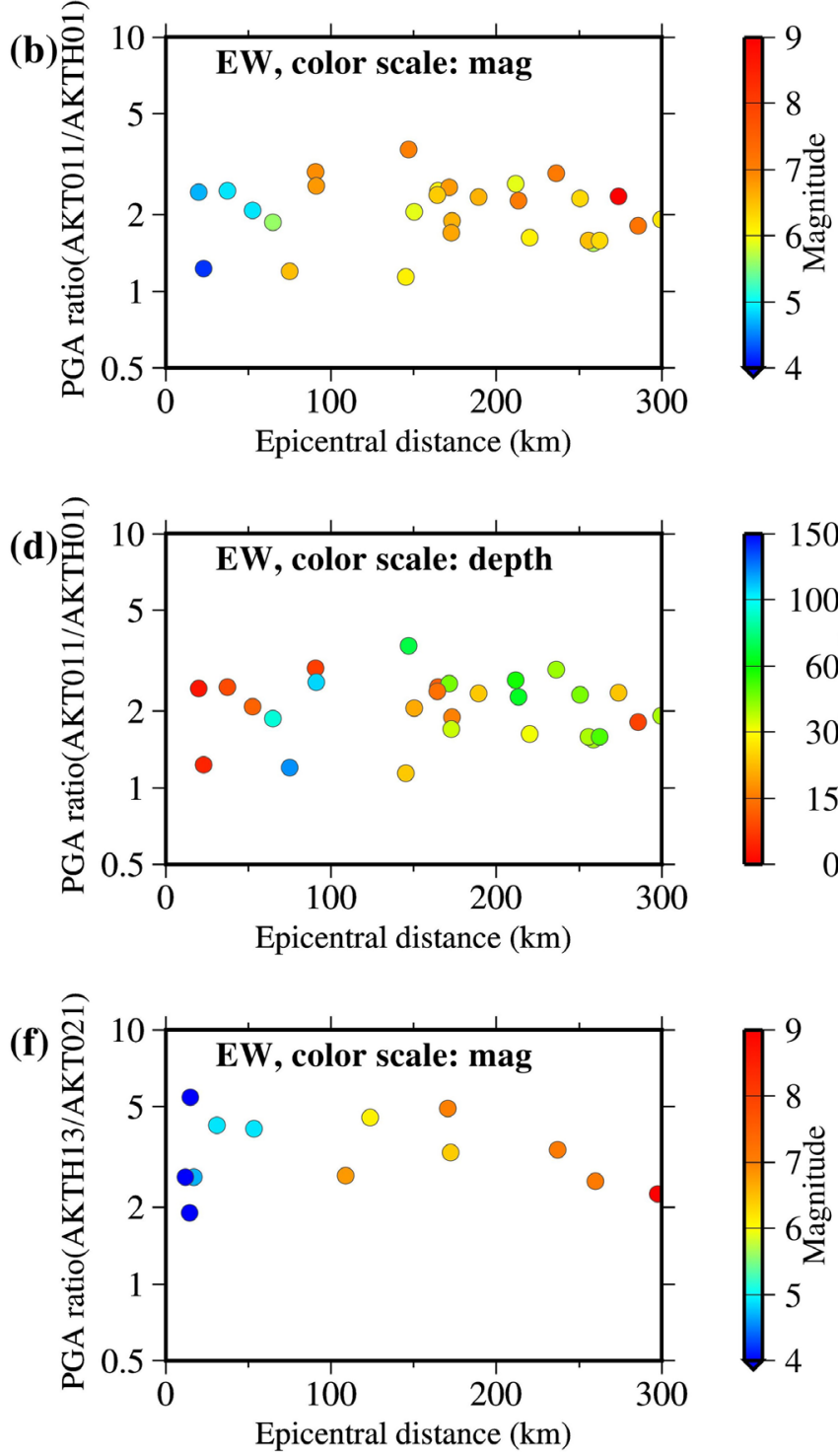

(h)

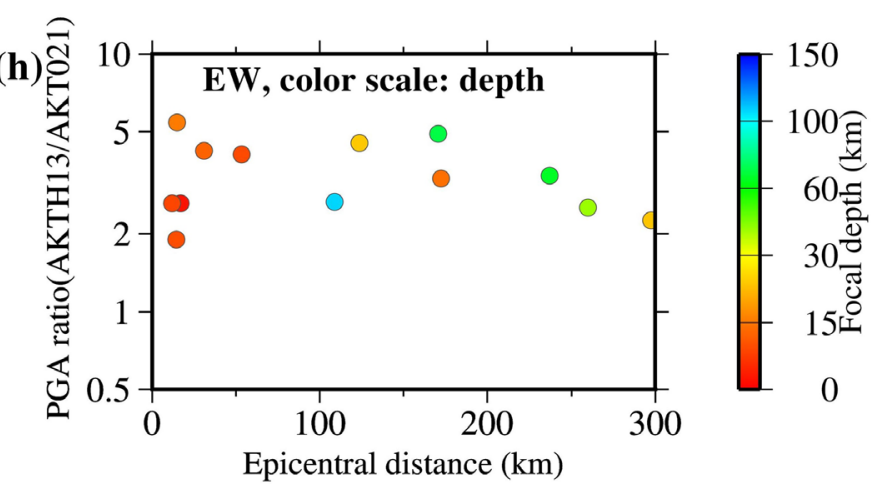

Fig. 9: Ratios of PGAs of AKT011 and AKTH01as a function of hypocentral distance for the NS (a, c) and EW (b, d) components. The ratios are color-coded by magnitude scale in $\mathbf{a}, \mathrm{b}$, and depth scale in $\mathrm{c}, \mathrm{d}$. Similar to the abovementioned, panels e, f, g, and $h$ show the ratios of PGAs of AKTH13 and AKT021. 
the AKTH13 and AKT021 (Fig. 9e, f, g, h). A major difference is that the ratios scatter largely for this pair, especially at small distances (epicentral distance < $20 \mathrm{~km}$ ), and the data are from events of $\mathrm{Mw}<5$. As the inter-station separation is considerably large for this pair $(\sim 1.5 \mathrm{~km})$ compared to the first pair $(\sim 250$ $\mathrm{m})$, the source radiation pattern may be different for the nearby earthquakes. Nonetheless, the ratios were systematically larger than around unity. The mean PGA ratios computed from 13 events were around 3.7 and 3.4 for the NS and EW components, respectively. The ratios for the PGAs are also plotted as a function of back azimuth (direction from site to epicenter measured from the north) in Fig. 10 to see the directional dependence of site amplification. The back azimuths were with respect to the sites AKT011 and AKTH13 for the first and second pairs, respectively. The PGA ratios did not show any dependency on back azimuths for the first pair (Fig. 10a, b). However, the PGA ratios for the second pair showed a tendency to increase with back azimuths. The trend is evident in the plot for the EW components (Fig. 10d). However, a careful examination of the plot in Fig. 10(d) also reveals that the trend is mainly due to the events at smaller epicentral distances. This may indicate that the radiation pattern effect may differ from the second pair due to their larger inter-station separation than the first pair of stations.

(a)

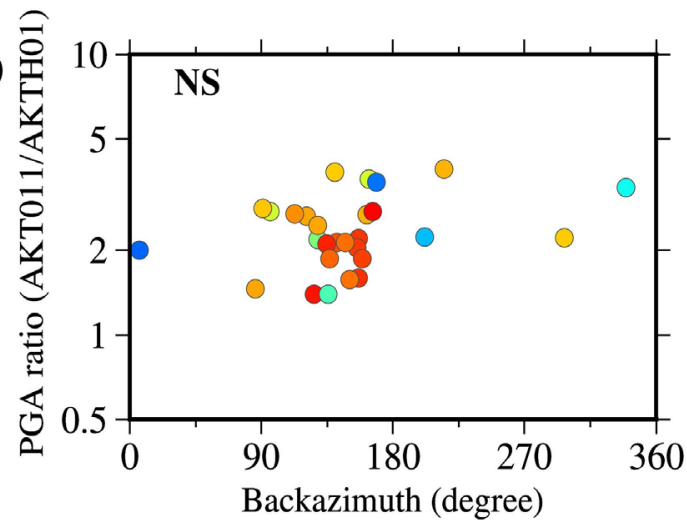

(c)

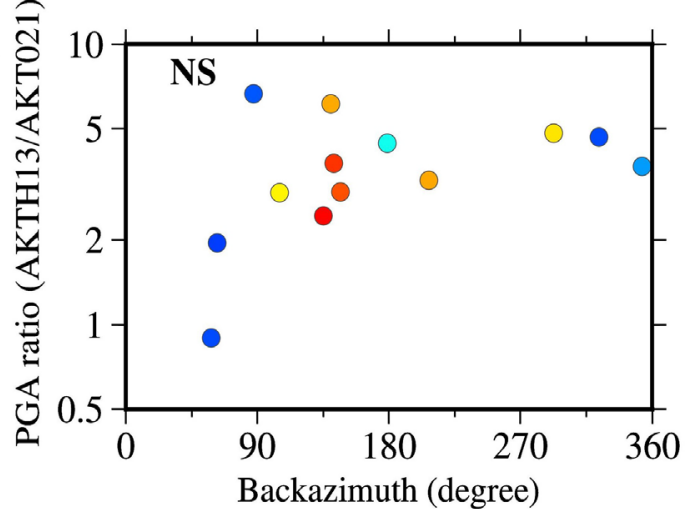

We examined the ratios of the PGVs at the two pairs of stations for the same set of data used to analyze the PGA ratios discussed above. The ratios of the PGVs as a function of epicentral distance are shown in Fig. 11 , and the ratios as a function of back azimuth are plotted in Fig. 12. The main difference between the plots for the PGAs and PGVs is that the ratios are smaller for the PGVs on average. The mean ratios are around 1.6 and 1.5, respectively, for the NS and EW components of the first pair of stations. The values of the mean ratios for the second pair are around 2.3 and 1.8 for the NS and EW components, respectively. The differences between the two components of each pair are generally similar for the PGAs and PGVs, the values for the NS component being larger than those for the EW components. Other properties such as the larger scattering of the ratios and distance dependency, all follow the similarity to the ratios of the PGAs. The dependence on backazimuth is not so clear for the PGVs.

\section{DISCUSSIONS AND CONCLUSIONS}

We analyzed the strong-motion records during the 2017 AP earthquake at two pairs of stations. The stations in each pair were located closely, and the PGAs were more substantial at the sites with smaller $\mathrm{S}$-wave velocities in the upper layers. Available PS-

Fig. 10: Ratios of PGAs at AKT011 and AKTH01 (a, b) and AKTH13 and AKT021 (c, d) as a function of hypocentral distance for the NS and EW components indicated in the plots. The values are color-coded by back azimuths. 

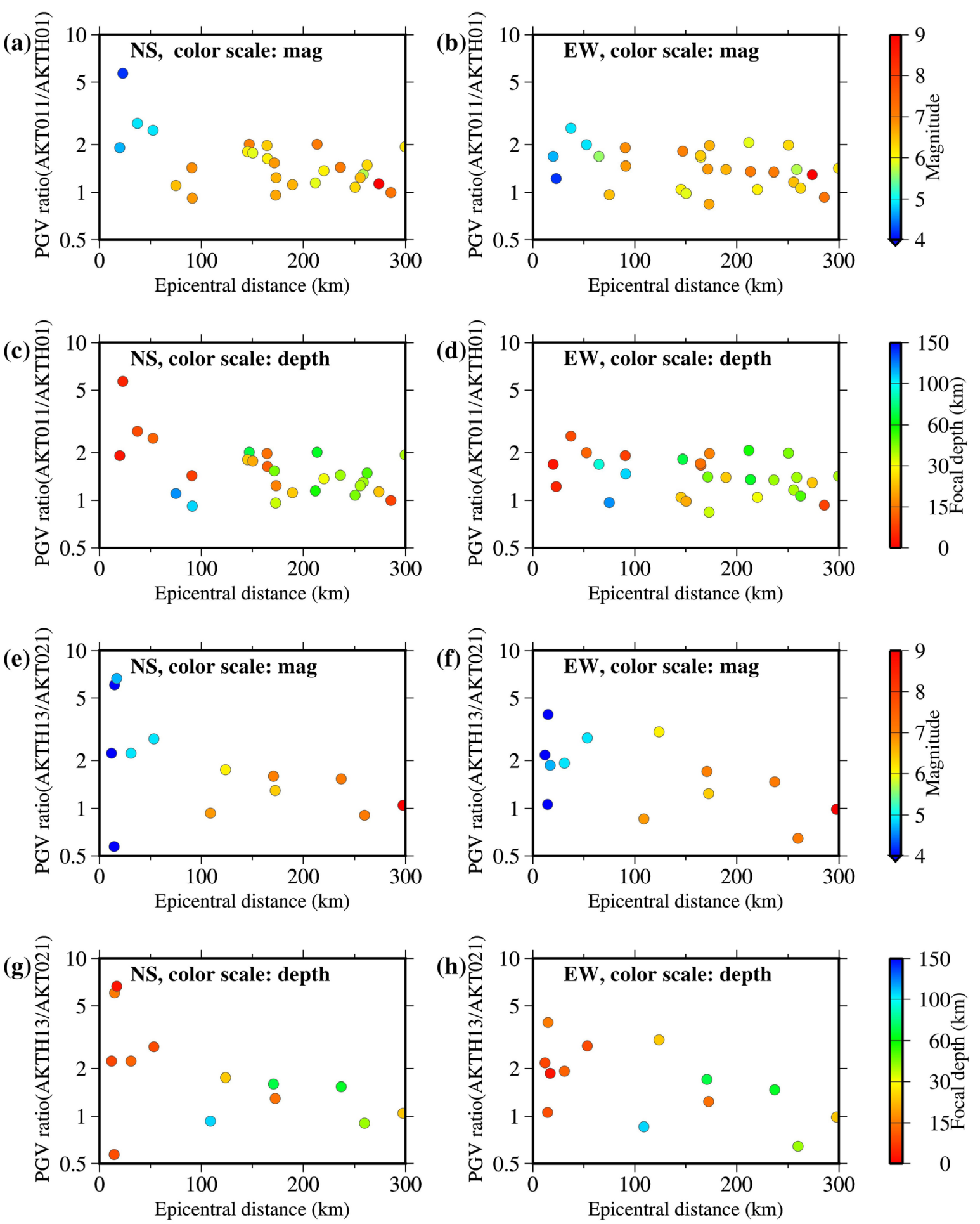

Fig. 11: Ratios of PGVs of AKT011 and AKTH01 as a function of hypocentral distance for the NS (a, c) and EW $(b, d)$ components. The ratios are color-coded by magnitude scale in $a, b$, and by depth scale in $c$, d. Similar to the abovementioned, panels e, f, g, and h show the ratios of PGVs of AKTH13 and AKT021.

logging velocity models suggested larger amplification at frequencies over about $3 \mathrm{~Hz}$ at the sites with larger PGAs. Interestingly, the PGAs at the stations of each pair were more significant at frequencies of 3 to 10 $\mathrm{Hz}$ and were close to the observed PGAs compared to the PGAs at other frequency bands at the respective stations. The larger PGAs at the common frequency band of 3 to $10 \mathrm{~Hz}$ may indicate that the input motions were also rich in the frequency band.
We compared the PGAs and PGVs at the stations of each pair for several earthquakes to investigate that the above differences were earthquake specific or not. We found that the PGAs and PGVs were systematically larger at the sites with lower S-wave velocities in the upper layers in each pair. Also, the ratios for the PGAs were generally larger than the ratios for the $\mathrm{PGVs}$ between the stations of each pair, since the accelerations are richer in short period 
(a)

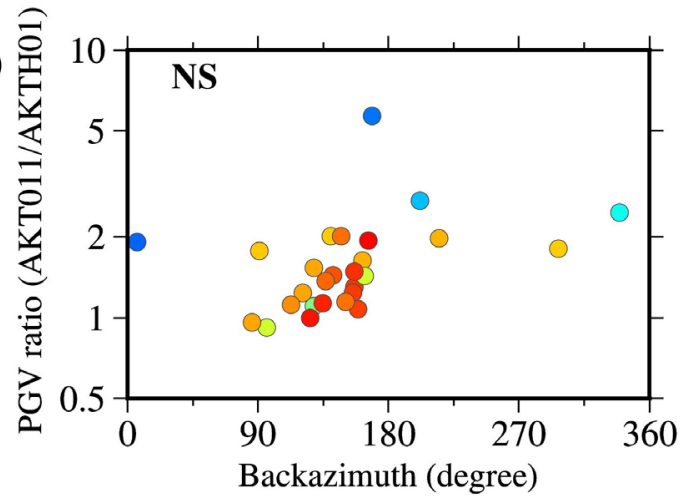

(c)

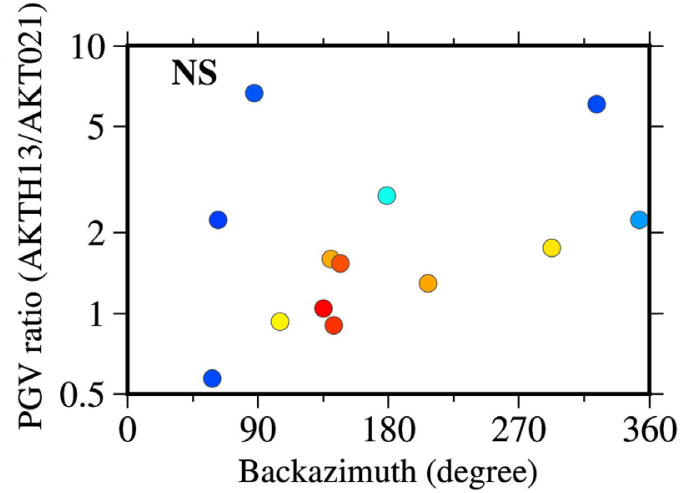

(b)

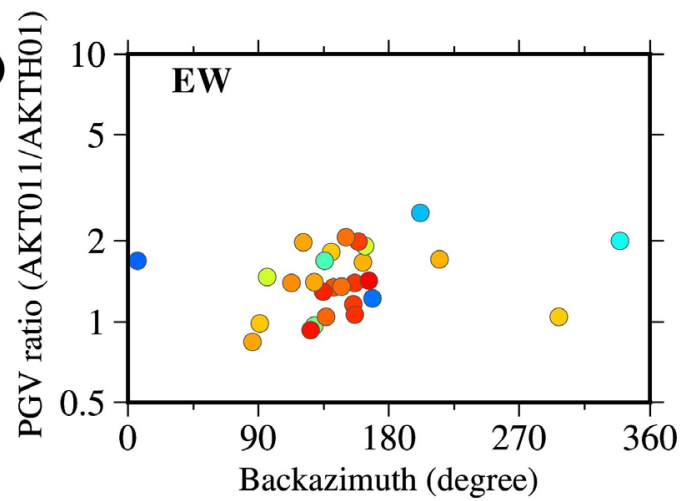

(d)

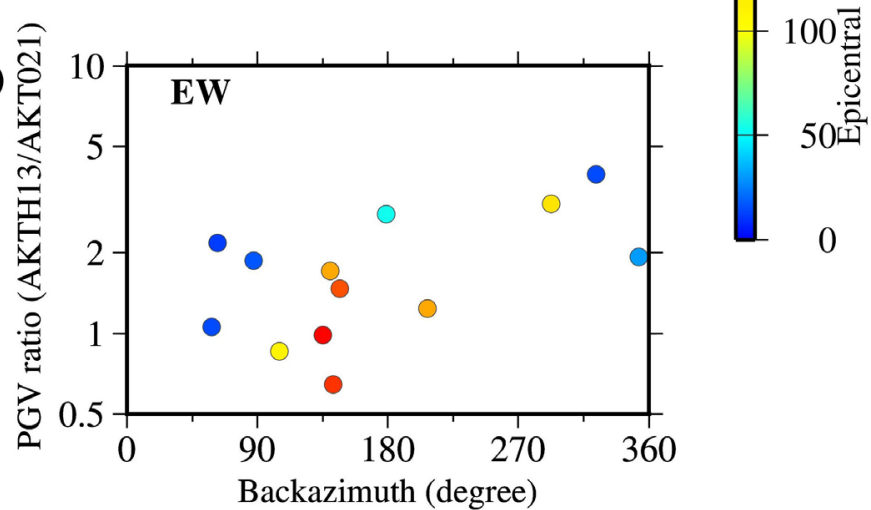

Fig. 12: Ratios of PGVs at AKT011 and AKTH01 (a, b) and AKTH13 and AKT021 (c, d) as a function of hypocentral distance for the NS and EW components indicated in the plots. The values are color-coded by back azimuths.

components than velocities. The velocity models also suggested larger amplification at short periods (high frequencies). Thus, we conclude that the larger ratios for the PGAs were related to the S-wave velocity differences in the shallow layers between the adjacent sites.

The present analysis revealed that the PGA ratios between the sites of each pair and also the PGV ratios were mostly independent or slightly related to the epicentral distances and focal depths. The ratios were slightly smaller for epicentral distances over about $200 \mathrm{~km}$. We found that the PGA and PGV ratios were scattered largely for nearby events for the pair of stations with larger inter-station distance. One interesting observation was that the PGA ratios showed an apparent dependence on the back azimuths for the pair of stations with larger inter-station separation, while it was not so clear for the ratios of the PGVs. We noted that the apparent dependency on back azimuth was related mostly to the nearby small events, and the difference of the source radiation between two stations may not be negligible at the higher frequencies. However, as the large ratios were observed even for the distant earthquakes, we conclude that the site-related amplification was the most dominant factor for the differences of the PGAs and PGVs between the nearby stations.

Finally, we note that the structural damage of an engineering structure depends not only on the PGA, but also on other factors such as the vulnerability of the structures. It is a common practice to avoid the peak vibration period of the ground in the engineering design of structures. It is expected that the results presented in the paper will be helpful towards understanding the variability of strong motions for microzonation and so on.

\section{ACKNOWLEDGMENTS}

We would like to thank the Japan Meteorological Agency for providing us with hypocenter information for the earthquakes used in this study. We would also like to thank Wessel and Smith (1998) for providing us with Generic Mapping Tools, which were used to make some figures in the manuscript. We would like to thank Dr. Deepak Chamlagain for arranging a review of the manuscript and two anonymous reviewers for the helpful comments.

\section{DATA AND RESOURCES}

The strong-motion (K-NET and KiK-net) recordings and PS-loggings used in this study were downloaded from the website: http://www.kyoshin.bosai.go.jp/. The hypocenter locations and JMA magnitudes for the earthquakes used for the compariosn of the peak ground motions were taken from the website: http:// www.data.jma.go.jp/svd/eqev/data/bulletin/index. $\mathrm{html}$. The hypocenter locations and JMA magnitudes for aftershocks were taken from the website: https:// 
www.data.jma.go.jp/svd/eqev/data/daily_map/index. html. The moment magnitudes estimated by F-net NIED were taken from the website: http://www.fnet. bosai.go.jp/event/joho.php?LANG=en.

\section{AUTHOR'S CONTRIBUTIONS}

Y.P. Dhakal conceptualized the study, analyzed the data, and drafted the manuscript. W. Suzuki, T. Kimura, T. Kunugi, and S. Aoi provided helpful comments. All authors read and approved the manuscript.

\section{REFERENCES}

Aki, K., Richards. P.G., 2002, Quantitative seismology. Second ed. University Science Books.

Aoi, S., Asano, Y., Kunugi, T., Kimura, T., Uehira, K., Takahashi, N., Ueda, H., Shiomi, K., Matsumoto, T., and Fujiwara, H., 2020, MOWLAS: NIED observation network for earthquake, tsunami and volcano. Earth Planets Space, v. 72:126. https://doi.org/10.1186/ s40623-020-01250-x

Bijukchhen, S.M., Takai, N., Shigefuji, M., Ichiyanagi, M., Sasatani, T., Sugimura, Y., 2017, Estimation of 1-D velocity models beneath strong-motion observation sites in the Kathmandu Valley using strong-motion records from moderate-sized earthquakes. Earth Planets Space, v. 69:97. https://doi.org/10.1186/ s40623-017-0685-4

Celebi, M., Prince, J., Dietel, M., Onate, M., and Chavez, G., 1987, The culprit in Mexico City-amplification of motions. Earthquake Spectra, v. 3, pp 315-328.

Fujiwara, H., Kawai, S., Aoi, S., Morikawa, N., Senna, S., Kudo, N., Ooi, M., Hao, K. X.S., Hayakawa, Y., Toyama, N., Matsuyama, H., Iwamoto, K., Suzuki, H., and Ryu, E., 2009, A Study on subsurface structure model for deep sedimentary layers of Japan for strongmotion evaluation. Technical Note of the National Research Institute for Earth Science and Disaster Prevention No.337 (in Japanese).

J-SHIS (Japan Seismic Hazard Information Station), 2020, http://www.j-shis.bosai.go.jp/en/downloads (last accessed in March, 2020).

Kawase, H., 1996, The cause of the damage belt in Kobe: the basin-edge effect, constructive interference of the direct S-wave with the basin-induced diffracted/Rayleigh waves. Seismol. Res. Lett., v. 67(5), pp. 25-34.

Kramer, S.L., 1996, Geotechnical earthquake engineering. Prentice-Hall Inc: 653p.

Kudo, K., and Shima, E., 1970, Attenuation of shear waves in soil. Bull. Earthq. Res. Inst., Univ. Tokyo, v. 48, pp. 145-158.

Nagashima, F., Matsushima, S., Kawase, H., SánchezSesma, F.J., Hayakawa, T., Satoh, T., and Oshima, M., 2014, Application of horizontal-to-vertical spectral ratios of earthquake ground motions to identify subsurface structures at and around the K-NET site in Tohoku, Japan. Bull. Seismol. Soc. Am., v. 104 (5), pp. 2288-2302. https://doi.org/10.1785/0120130219

National Research Institute for Earth Science and Disaster Resilience, 2019, NIED K-NET, KiK-net, National Research Institute for Earth Science and Disaster Resilience. https://doi.org/10.17598/NIED.0004

Okada, Y., Kasahara, K., Hori, S., Obara, K., Sekiguchi, S., Fujiwara, H., and Yamamoto, A., 2004, Recent progress of seismic observation networks in Japan Hi-net, F-net, K-NET and KiK-net-. Earth Planets Space, v. 56:xv-xxviii. https://doi.org/10.1186/ BF03353076

Pinzón, L.A., Pujades, L.G., Macau, A., and Figueras, S., 2019, Increased seismic hazard in Barcelona (Spain) due to soil-building resonance effects. Soil. Dyn. Earthq. Eng., v. 117, pp. 245-250. https://doi. org/10.1016/j.soildyn.2018.11.022

RGAFJ (Research Group for Active Faults of Japan), 1991, Active faults in Japan: sheet maps and inventories (revised edition). University of Tokyo Press. (in Japanese with English summary).

Rodríguez, V.H.S., and Midorikawa, S., 2003, Comparison of spectral ratio techniques for estimation of site effects using microtremor data and earthquake motions recorded at the surface and in boreholes. Earthquake Engng. Struct. Dyn., v. 32(11), pp. 16911714. https://doi.org/10.1002/eqe.296

Si, H., and Midorikawa, S., 1999, New attenuation relations for peak ground acceleration and velocity considering effects of fault type and site condition. Journal of Structural and Construction Engineering, Transactions of AIJ, v. 523, pp. 63-70. https://doi. org/10.3130/aijs.64.63_2 (in Japanese with English abstract)

Si, H., and Midorikawa, S., 2000, New attenuation relations for peak ground acceleration and velocity considering effects of fault type and site condition. In: Proceedings of the 12th World Conference on Earthquake Engineering, Auckland, New Zealand. Paper ID 0532.

Steidl, J.H., Tumarkin, A.G., and Archuleta, R.J., 1996, What is a reference site? Bull. Seismol. Soc. Am., v. 86, pp. 1733-1748.

Wessel, P., and Smith, W.H.F., 1998, New, improved version of generic mapping tools released. Eos trans AGU, v. 79, pp. 579. https://doi.org/10.1029/98EO00426

Yamamizu, F., Goto, N., Ohta, Y., and Takahashi, H., 1983, Attenuation of shear waves in deep soil deposits as revealed by down-hole measurements in the 2,300 meter-borehole of the shimohsa observatory, Japan. J. Phys. Earth, v. 31 (2), pp. 139-157.

Yamanaka, H., Chimoto, K., Miyake, H., Tsuno, S., and Yamada, N., 2016, Observation of earthquake ground motion due to aftershocks of the 2016 Kumamoto earthquake in damaged areas. Earth, Planets and Space, v. 68:197. https://doi.org/10.1186/s40623-0160574-2. 


\section{APPENDIX 1}

List of events used to compare the PGAs and PGVs explained in the main text. The values are in the km unit under the Depth column. Under the column F-net, * indicates that the Mw value of 9 was adopted from JMA; Mw estimated by F-net was equal to 8.7.

\begin{tabular}{|c|c|c|c|c|c|c|}
\hline \multirow{2}{*}{ Date (JST) } & \multicolumn{4}{|c|}{ JMA } & \multirow{2}{*}{$\frac{\text { F-net }}{\mathrm{Mw}}$} & \multirow{2}{*}{ Availability to } \\
\hline & Lon & Lat & Depth & $\mathrm{Mj}$ & & \\
\hline 20011202, 22:02 & 39.3955 & 141.2667 & 121.5 & 6.4 & 6.5 & 1st pair \\
\hline 20030303, 07:47 & 37.6847 & 141.787 & 41.2 & 5.8 & 5.7 & 1st pair \\
\hline 20030526, 18:24 & 38.8057 & 141.6825 & 70.7 & 7.0 & 7.0 & both pair \\
\hline 20030726, 07:13 & 38.402 & 141.1745 & 11.9 & 6.4 & 6.1 & 1st pair \\
\hline 20050816, 11:46 & 38.1507 & 142.2795 & 41.6 & 7.2 & 7.1 & both pair \\
\hline $20070307,21: 59$ & 40.0895 & 140.3048 & 15.5 & 4.2 & 4.0 & 2nd pair \\
\hline 20080614, 08:43 & 39.0298 & 140.8807 & 7.8 & 7.2 & 6.9 & 1st pair \\
\hline $20080724,00: 26$ & 39.732 & 141.6353 & 108.1 & 6.8 & 6.8 & both pair \\
\hline $20100314,17: 08$ & 37.7242 & 141.818 & 39.8 & 6.7 & 6.5 & 1st pair \\
\hline $20110309,11: 45$ & 38.3285 & 143.2798 & 8.3 & 7.3 & 7.2 & 1st pair \\
\hline $20110311,14: 46$ & 38.1035 & 142.861 & 23.7 & 8.4 & $9.0^{*}$ & both pair \\
\hline $20110311,16: 29$ & 39.0225 & 142.3112 & 16.0 & 6.6 & 6.6 & 1st pair \\
\hline 20110311, 20:37 & 39.1697 & 142.6192 & 24.0 & 6.7 & 6.6 & 1st pair \\
\hline 20110312, 04:47 & 40.4168 & 139.0697 & 24.0 & 6.4 & 6.1 & both pair \\
\hline 20110312, 22:15 & 37.1975 & 141.4263 & 40.1 & 6.2 & 6.2 & 1st pair \\
\hline 20110328, 07:24 & 38.3837 & 142.3463 & 31.7 & 6.5 & 6.1 & 1st pair \\
\hline 20110401, 19:49 & 40.2568 & 140.364 & 12.4 & 5.0 & 4.9 & both pair \\
\hline $20110407,23: 32$ & 38.2028 & 141.9237 & 65.7 & 7.1 & 7.1 & both pair \\
\hline 20110527, 22:33 & 39.6122 & 140.6323 & 4.5 & 4.6 & 4.2 & 1st pair \\
\hline 20110623, 06:51 & 39.9478 & 142.5908 & 36.4 & 6.9 & 6.7 & 1st pair \\
\hline 20110725, 03:51 & 37.7087 & 141.6267 & 45.8 & 6.3 & 6.3 & 1st pair \\
\hline $20110819,14: 36$ & 37.649 & 141.7967 & 51.2 & 6.5 & 6.3 & 1st pair \\
\hline 20120210, 13:56 & 40.0505 & 140.5518 & 9.7 & 3.8 & 3.9 & 2nd pair \\
\hline 20120327, 20:00 & 39.8063 & 142.3338 & 20.5 & 6.6 & 5.9 & 1st pair \\
\hline 20121006, 01:19 & 39.9897 & 140.6067 & 2.5 & 4.9 & 4.7 & both pair \\
\hline 20130804, 12:29 & 38.1627 & 141.8025 & 58.0 & 6.0 & 5.9 & 1st pair \\
\hline 20140615, 02:31 & 39.3962 & 141.1077 & 93.9 & 5.5 & 5.6 & 1st pair \\
\hline 20150513, 06:13 & 38.8628 & 142.1502 & 46.2 & 6.8 & 6.8 & 1st pair \\
\hline 20150924, 15:19 & 40.0315 & 140.5307 & 8.7 & 3.9 & 3.9 & 2nd pair \\
\hline 20170908, 22:23 & 39.5012 & 140.4193 & 9.4 & 5.2 & 4.9 & both pair \\
\hline 20190618, 22:22 & 38.608 & 139.4793 & 14.0 & 6.7 & 6.4 & both pair \\
\hline
\end{tabular}


